\title{
Multistage Dynamic Optimization with Different Forms of Neural-State Constraints to Avoid Many Object Collisions Based on Radar Remote Sensing
}

\author{
Józef Lisowski (D) \\ Faculty of Marine Electrical Engineering, Gdynia Maritime University, 81-225 Gdynia, Poland; \\ j.lisowski@we.umg.edu.pl
}

Received: 19 February 2020; Accepted: 20 March 2020; Published: 22 March 2020

\begin{abstract}
This article presents the possibility of helping navigators direct the movement of an object, while safely passing through other objects, using an artificial neural network and optimization methods. It has been shown that the best trajectory of an object in terms of optimality and security, from among many possible options, can be determined by the method of dynamic programming with the simultaneous use of an artificial neural network, by depicting the encountered objects as moving in forbidden domains. Analytical considerations are illustrated with examples of simulation studies of the developed calculation program on real navigational situations at sea. This research took into account both the number of objects encountered and the different shapes of domains assigned to the objects encountered. Finally, the optimal value of the safe object trajectory time was compared on the setpoint value of the safe passing distance of objects in given visibility conditions at sea, and the degree of discretization of calculations was determined by the density of the location of nodes along the route of objects.
\end{abstract}

Keywords: radar; safe control; optimization; neural network; computer simulation

\section{Introduction}

The International Maritime Organization (IMO) has introduced the requirement for objects to have an automatic radar plotting device, called an Automatic Radar Plotting Aid (ARPA), installed. This system automatically initiates and continues the tracking of detected echoes, generating alarms in hazardous situations, and was presented by Graziano et al. and Huang et al. in their research [1,2]. The ARPA computer calculates the distance and time for the critical approach of objects and then compares the obtained values with their recommended values for the current situation at sea. If the calculated values exceed the set limits, the dangerous target alarm is activated. It is also possible to simulate a trial maneuver of the object, but only for one target, namely the most dangerous encountered object. This process helps the navigator evaluate the effects of the planned anti-collision maneuver at an accelerated timescale. Therefore, as stated by Bist [3], the ARPA is a source of support for the work of the navigator, increasing navigational safety. The main task of ARPA is to prepare for maneuvering decisions made by the navigator, especially in situations of concentrated object traffic in restricted waters [4-6].

In practice, there are many possible safe collision-avoidance maneuvers; ideally, the navigator chooses the optimal maneuver, which is the one that, in addition to minimizing the collision risk, results in the smallest deviation from the original path. The possibilities for supplementing the system with appropriate methods to support maneuvering decisions taken in an uncertain navigational situation that occurs in a short time in relation to the greater number of objects encountered are described in [7-12]. The process of reducing the uncertainty when assessing the real navigational 
situation of an object by using an artificial neural network is shown in [13-15]. Lenart [16] proposed the parameter "time for a safe distance" after detecting dangerous objects as a potentially important parameter, accompanied by the display of possible evasive maneuvers. Borkowski [17] presented acceptable solutions for altering the course range in compliance with the International Regulations for Preventing Collisions at Sea (COLREGs Rules). Liu et al. and Lisowski $[18,19]$ proposed a different approach to preventing object collisions at sea, through use of game-theory methods to determine the safe trajectory of ships by considering elements of an indefinite nature in real navigational situations at sea.

In previous works, the subjectivity of the navigator making a maneuvering decision in a collision situation has been omitted in the calculation algorithms, however this subjectivity is a factor in $88 \%$ of accidents at sea. This is why the purpose of this article is the synthesis of an algorithm for safe and optimal object control in situations where several objects pass by, using an artificial neural network and generating subjective domains of passing objects and the Bellman dynamic-programming method.

\section{ARPA Radar Remote Anti-Collision Process Sensing}

The purpose of the navigator's decision-support system is to propose a sequence of maneuvers that have been determined by anti-collision calculations. These calculations are carried out by a specific algorithm that determines a safe trajectory for the object on the basis of input data that describe the current navigational situation. If during calculations one of the encountered objects in question changes course or speed, it is necessary to repeat the calculations, which therefore last only a dozen or so seconds. Figure 1 shows that the parameters that are needed to perform these calculations are the parameters of the object.

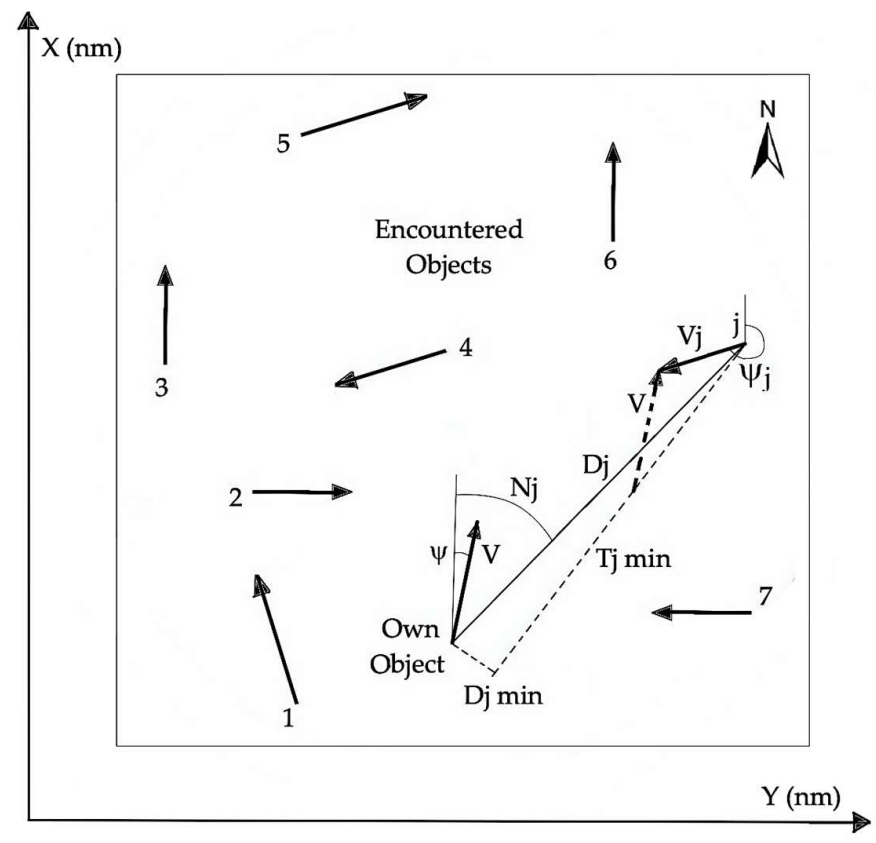

Figure 1. Radar imaging of passing objects: $\mathrm{X}, \mathrm{Y}$-objects position coordinates; $\mathrm{V}, \psi$-speed and course, respectively, of own object; $V_{j}, \psi_{j}$-speed and course, respectively, of $j$ object; $D_{j}, N_{j}$-distance and bearing in relation to $j$ object; $D_{j \min }, T_{j \text { min }}$-distance and time for critical passing of objects.

The calculation process consists of downloading the needed data for the anti-collision calculations from ARPA, entering these data into the program that implements the selected safe object-control algorithm, and displaying the calculation results as an illustration of the designated route of the object and giving the value of its final deviation from the reference cruise route. 
In addition to accessing the ARPA, the designed system includes an external microcontroller with specialized software that manages communication and performs anti-collision calculations. The integrated application that supports communication and determines the safe trajectory of the object was created in the MATLAB environment.

\section{Dynamic Programming Algorithm with an Artificial Neural Network Procedure}

The Dynamic Programming method with Artificial Neural Network constraints (DPANN) was then entered into the MATLAB command window (Figure 2).

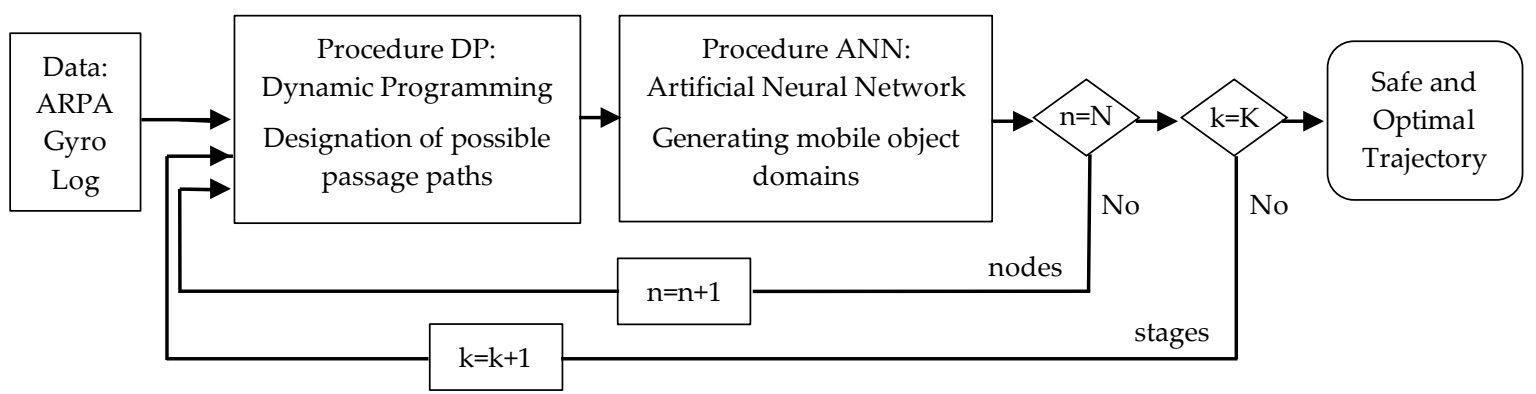

Figure 2. Block diagram of the Dynamic Programming with Artificial Neural Network constraints (DPANN) algorithm for determining a safe and optimal object trajectory.

The first stage of the application's operation is the introduction of simulation parameters, such as maneuvering time, advance time, safe distance, deviation at which the speed reduction was to occur, and the percentage by which the speed was to be reduced. These parameters can be manually entered, or their default values can be set. The default values of these parameters set in the program were as follows: maneuver time $=3 \mathrm{~min}$; advance time $=3 \mathrm{~min}$; safe distance $=1$ nautical mile; deviation from the set course at which the speed was to be reduced $=361$ degrees; and the percentage by which the speed had been reduced $=30 \%$. In the next step, communication with the ARPA was performed, and the necessary information to perform the anti-collision calculations was downloaded. Before transmitting the signal, the communication-port identifier to be used was determined.

The downloaded frames were analyzed in order to extract the parameters needed for the anti-collision calculations, and these selected parameters were saved in the appropriate format. When the transmission of all necessary data was completed, the communication port was closed, and the automatic transition of the program realized the anti-collision calculations. The last stage of the application's operation was the presentation of the calculation results. The application could then be terminated, or the whole process could be repeated.

\subsection{Dynamic Programming of the Safe and Optimal Object Trajectory}

In the basic problem of optimal control with a discrete time $\mathbf{k}$, the quality index $\mathbf{I}$ is minimized:

$$
\mathbf{I}(\mathbf{x}, \mathbf{u})=\sum_{\mathbf{k}=1}^{\mathbf{K}} \mathbf{f}_{\mathbf{o}}(\mathbf{x}(\mathbf{k}), \mathbf{u}(\mathbf{k}), \mathbf{k})
$$

where $\mathbf{x}$ and $\mathbf{u}$ are the state and control, respectively, of the object, which is described by the state equation:

$$
\mathbf{x}(\mathbf{k}+1)=\mathbf{f}(\mathbf{x}(\mathbf{k}), \mathbf{u}(\mathbf{k}), \mathbf{k}) \mathbf{k}=1,2, \ldots, \mathbf{K}
$$

with given initial and final conditions:

$$
\mathbf{x}(0)=\mathbf{x}_{0}, \mathbf{x}(\mathbf{K})=\mathbf{x}_{\mathbf{K}} .
$$


and limitations for control variables and constraints of individual variables describing the state of the process:

$$
\mathbf{u}(\mathbf{k}) \in \mathbf{U}, \mathbf{x}(\mathbf{k}) \in \mathbf{X}
$$

The essence of the method of discrete dynamic programming is the following Bellman recursive equation:

$$
\begin{gathered}
\mathbf{L}(\mathbf{x}(\mathbf{k}), \mathbf{k})=\min _{\mathbf{u}(\mathbf{k}) \in \mathbf{U}}\left(\mathbf{f}_{\mathbf{o}}(\mathbf{x}(\mathbf{k}), \mathbf{u}(\mathbf{k}), \mathbf{k})+\mathbf{L}(\mathbf{f}(\mathbf{x}(\mathbf{k}), \mathbf{u}(\mathbf{k}), \mathbf{k}), \mathbf{k}+1)\right. \\
\mathbf{k}=\mathbf{K}-1, \mathbf{K}-2, \ldots, 1 \\
\mathbf{L}(\mathbf{x}(\mathbf{K}), \mathbf{K})=0
\end{gathered}
$$

where $\mathbf{L}$ represents the minimum value of the control quality index $\mathbf{I}$; that is, in the safe ship control considered in the article, the minimum time needed to safely reach the nearest turning point on a given cruise trajectory.

This allows determination of the optimal controls:

$$
\left\{\mathbf{u}^{*}(\mathbf{k}), \mathbf{k}=1,2, \ldots, \mathbf{K}\right\}
$$

Considering the description of the hydrodynamic properties of the sea object in the form of appropriate differential equations and then transforming them, the following mathematical relationships are obtained:

$$
\left.\begin{array}{l}
\mathrm{x}_{1, \mathrm{k}+1}=\mathrm{x}_{1, \mathrm{k}}+\mathrm{x}_{5, \mathrm{k}} \cdot \Delta \mathrm{t}_{\mathrm{k}+1} \cdot \sin \mathrm{x}_{3, \mathrm{k}} \\
\mathrm{x}_{2, \mathrm{k}+1}=\mathrm{x}_{1, \mathrm{k}}+\mathrm{x}_{5, \mathrm{k}} \cdot \Delta \mathrm{t}_{\mathrm{k}+1} \cdot \cos \mathrm{x}_{3, \mathrm{k}} \\
\mathrm{x}_{3, \mathrm{k}+1}=\mathrm{x}_{3, \mathrm{k}}+\mathrm{x}_{4, \mathrm{k}} \cdot \Delta \mathrm{t}_{\mathrm{k}+1} \\
\mathrm{x}_{4, \mathrm{k}+1}=\mathrm{x}_{4, \mathrm{k}}+\frac{1}{\mathrm{~T}_{1}}\left(-\mathrm{x}_{4, \mathrm{k}}-\mathrm{a}_{1} \cdot \mathrm{x}_{4, \mathrm{k}}\left|\mathrm{x}_{4, \mathrm{k}}\right|+\mathrm{k}_{1} \alpha_{\max } \cdot \mathrm{u}_{1, \mathrm{k}}\right) \Delta \mathrm{t}_{\mathrm{k}+1} \\
\mathrm{x}_{5, \mathrm{k}+1}=\mathrm{x}_{5, \mathrm{k}}+\mathrm{x}_{6, \mathrm{k}} \cdot \Delta \mathrm{t}_{\mathrm{k}+1} \\
\mathrm{x}_{6, \mathrm{k}+1}=\mathrm{x}_{6, \mathrm{k}}+\frac{1}{\mathrm{~T}_{2} \mathrm{~T}_{3}}\left[-\left(\mathrm{T}_{2}+\mathrm{T}_{3}\right) \mathrm{x}_{6, \mathrm{k}}-\mathrm{x}_{5, \mathrm{k}}+\mathrm{k}_{2} \cdot \mathrm{n}_{\max } \cdot \mathrm{u}_{2, \mathrm{k}}\right] \Delta \mathrm{t}_{\mathrm{k}+1}
\end{array}\right\}
$$

where $\mathrm{x}_{1}=\mathrm{X}_{0}, \mathrm{x}_{2}=\mathrm{Y}_{0}, \mathrm{x}_{3}=\psi, \mathrm{x}_{4}=\dot{\psi} . \mathrm{x}_{5}=\mathrm{V}, \mathrm{x}_{6}=\dot{\mathrm{V}}, \mathrm{u}_{1}=\alpha_{\mathrm{r}} / \alpha_{\max }, \mathrm{u}_{2}=\mathrm{n}_{\mathrm{r}} / \mathrm{n}_{\max }, \alpha_{\mathrm{r}}$ is the reference rudder angle; $n_{r}$ is the reference screw speed; $\psi$ is the object course; $\psi$ is the ship return speed; $V$ is linear speed; $\dot{V}$ is linear acceleration; $\left(\mathrm{X}_{0}, \mathrm{Y}_{0}\right)$ is the position of the object; $\mathrm{a}_{1}, \mathrm{k}_{1}$, and $\mathrm{k}_{2}$ are gain coefficients; and $\mathrm{T}_{1}, \mathrm{~T}_{2}$, and $\mathrm{T}_{3}$ are time constants of object dynamics.

The condition of the safe navigation of an object when meeting $\mathrm{j}$ other objects meets the restriction described by the following inequality:

$$
\mathrm{g}_{\mathrm{j}}\left(\mathrm{X}_{\mathrm{j}}(\mathrm{k}), \mathrm{Y}_{\mathrm{j}}(\mathrm{k}), \mathrm{k}\right) \geq 0
$$

where $g_{j}$ is the function describing the shape of the domain of the encountered object (for example, circles, hexagons, parabolas, ellipses), $\left(X_{j}, Y_{j}\right)$ is the position of the encountered object, and $k$ is the period of time discretization, ensuring compliance with the following condition of safe object traffic control:

$$
\mathrm{D}_{\mathrm{j} \min }>\mathrm{D}_{\mathrm{s}}
$$

where $D_{s}$ is the safe distance for approaching objects.

The object domains, described by Inequality (8), take different shapes that are determined with the help of software, such as the Neural Network Toolbox of the MATLAB software [20-23]. To avoid collision, there are many possible safe-course values and object speeds, and the optimal solution is chosen from this set of possibilities [24-26]. The minimal-collision-risk criterion is achieved by satisfying Inequality (8), which is equivalent to the object not disturbing the domain of another encountered object. Then, out of the many possible safe trajectories of the object that do not violate the 
areas of the encountered objects, the one that ensures the smallest deviation from the route while safely passing the objects is chosen.

In practice, considering the dynamics of the object, most collision situations are avoided by changing the course of the object while maintaining a constant speed. Then, the smallest deviation from the route of the object during the safe passing of encountered objects is equivalent to controlling the time-optimal movement of its own object:

$$
\mathrm{I}(\mathrm{x}, \mathrm{u}, \mathrm{k})=\sum_{\mathrm{k}=1}^{\mathrm{K}}\left(\mathrm{x}_{5}(\mathrm{k}), \mathrm{k}\right) \approx \mathrm{x}_{5} \sum_{\mathrm{k}=0}^{\mathrm{K}} \mathrm{k} \rightarrow \min \mathrm{t}_{\mathrm{K}}=\mathrm{t}_{\mathrm{K}}^{*} .
$$

The use of the principle of optimality allows calculation of the optimal strategy of the object, ensuring the minimal value of control purpose Function (9). According to this principle, regardless of initial state and control values, subsequent control decisions lead to optimal control associated with the first decision, and the appropriate calculations of the optimal solution run from the last to the first stage [27]. However, because the process of safe object control is subject to theoretical conditions of duality, the calculation of a safe object trajectory can be carried out from the first to the final stage $[28,29]$.

The optimal value of object-movement time in the first stage is as follows:

$$
\mathrm{t}_{1}^{*}=\Delta \mathrm{t}_{1}\left(\mathrm{x}_{1,0}, \mathrm{x}_{2,0}, \mathrm{x}_{3,0}, \mathrm{x}_{4,0}, \mathrm{x}_{5,0}, \mathrm{x}_{6,0}\right)
$$

The optimal value of object-movement time in the first two stages is as follows:

$$
t_{2}^{*}=t_{1}^{*}+\Delta t_{2}\left(x_{1,1}, x_{2,1}, x_{3,1}, x_{4,1}, x_{5,1}, x_{6,1}\right) .
$$

Finally, after mathematical derivation, optimal value of object-movement time in k stages is as follows:

$$
\begin{aligned}
\mathrm{t}_{\mathrm{k}}^{*}= & \min _{\mathrm{u}_{1, \mathrm{k}-2,} \mathrm{u}_{2, \mathrm{k}-2}}\left\{\mathrm{t}_{\mathrm{k}-1}^{*}\left[\mathrm{x}_{1, \mathrm{k}}, \mathrm{x}_{2, \mathrm{k}}, \mathrm{x}_{3, \mathrm{k}-1}, \mathrm{x}_{4, \mathrm{k}-1}, \mathrm{x}_{5, \mathrm{k}-1}, \mathrm{x}_{6, \mathrm{k}-1}\right]+\Delta \mathrm{t}_{\mathrm{k}}\left[\mathrm{x}_{1, \mathrm{k}}, \mathrm{x}_{2, \mathrm{k}}, \mathrm{x}_{1, \mathrm{k}+1}\left(\mathrm{x}_{1, \mathrm{k}}, \mathrm{x}_{3, \mathrm{k}}\left(\mathrm{x}_{3, \mathrm{k}-1}, \mathrm{x}_{4, \mathrm{k}-1}\right.\right.\right.\right. \\
& \left.\left.\left(\mathrm{x}_{4, \mathrm{k}-2}, \mathrm{u}_{1, \mathrm{k}-2}, \Delta \mathrm{t}_{\mathrm{k}-2}\right), \Delta \mathrm{t}_{\mathrm{k}-1}\right), \mathrm{x}_{5, \mathrm{k}}\left(\mathrm{x}_{5, \mathrm{k}-1}, \mathrm{x}_{6, \mathrm{k}-1},\left(\mathrm{x}_{6, \mathrm{k}-2}, \mathrm{u}_{2, \mathrm{k}-2}, \Delta \mathrm{t}_{\mathrm{k}-2}\right) \Delta \mathrm{t}_{\mathrm{k}-1}\right)\right), \\
& \mathrm{x}_{2, \mathrm{k}+1}\left(\mathrm{x}_{2, \mathrm{k}}, \mathrm{x}_{3, \mathrm{k}}\left(\mathrm{x}_{3, \mathrm{k}-1}, \mathrm{x}_{4, \mathrm{k}-1}\left(\mathrm{x}_{4, \mathrm{k}-2}, \mathrm{u}_{1, \mathrm{k}-2}, \Delta \mathrm{t}_{\mathrm{k}-2}, \Delta \mathrm{t}_{\mathrm{k}-1}\right) \mathrm{x}_{5, \mathrm{k}}\left(\mathrm{x}_{5, \mathrm{k}-1}, \mathrm{x}_{6, \mathrm{k}-1}\left(\mathrm{x}_{6, \mathrm{k}-2,}, \mathrm{u}_{2, \mathrm{k}-2}\right.\right.\right.\right. \\
& \left.\left.\left.\left.\left.\Delta \mathrm{t}_{\mathrm{k}-2}\right), \Delta \mathrm{t}_{\mathrm{k}-1}\right)\right), \mathrm{x}_{5, \mathrm{k}}\left(\mathrm{x}_{5, \mathrm{k}-1}, \mathrm{x}_{6, \mathrm{k}-1}\left(\mathrm{x}_{6, \mathrm{k}-2}, \mathrm{u}_{2, \mathrm{k}-2}, \Delta \mathrm{t}_{\mathrm{k}-2}\right), \Delta \mathrm{t}_{\mathrm{k}-1}\right)\right]\right\} \\
& \mathrm{k}=3,4, \ldots, \mathrm{K}
\end{aligned}
$$

The value of object-movement time $\Delta t_{k}$ in stage $k$ can be determined as follows:

$$
\Delta \mathrm{t}_{\mathrm{k}}=\frac{\Delta \mathrm{L}_{\mathrm{k}}\left(\mathrm{x}_{1, \mathrm{k}}, \mathrm{x}_{2, \mathrm{k}}, \mathrm{x}_{1, \mathrm{k}+1}, \mathrm{x}_{2, \mathrm{k}+1}\right)}{\mathrm{x}_{5, \mathrm{k}}} .
$$

where $\Delta \mathrm{L}_{\mathrm{k}}$ is object travel distance from $\left(\mathrm{x}_{1, \mathrm{k}}, \mathrm{x}_{2, \mathrm{k}}\right)$ to $\left(\mathrm{x}_{1, \mathrm{k}+1}, \mathrm{x}_{2, \mathrm{k}+1}\right)$.

The value of the optimal movement time along $\mathrm{k}$ stages depends on the location of the object at the $(\mathrm{k}-1)$ stage and control at the $(\mathrm{k}-2)$ stage. Moving from the first to last stage, Dependence (13) defines the functional equation for object steering by rudder angle $u_{1}$ and screw speed $u_{2}$. Limitations ensure that a safe approaching distance is maintained. To generate recommendations for a maneuver, priority safety (Equation (9)) checks that the positions of the met moving objects are not within the state constraints represented by the domain of the object. The node that is inside the domain is excluded from further calculations of the optimal object trajectory. The entire DPANN calculation program for determining an object trajectory consists of two procedures: dynamic-programming object-route optimization and an ANN creating domains of encountered objects [30].

The optimal trajectory is mathematically derived from Bellman's principle of optimality. First, all possible safe transition paths from start to end point are determined; then, a trajectory is determined from them that provides the smallest value of time for the object to cover this road (Figure 3). 


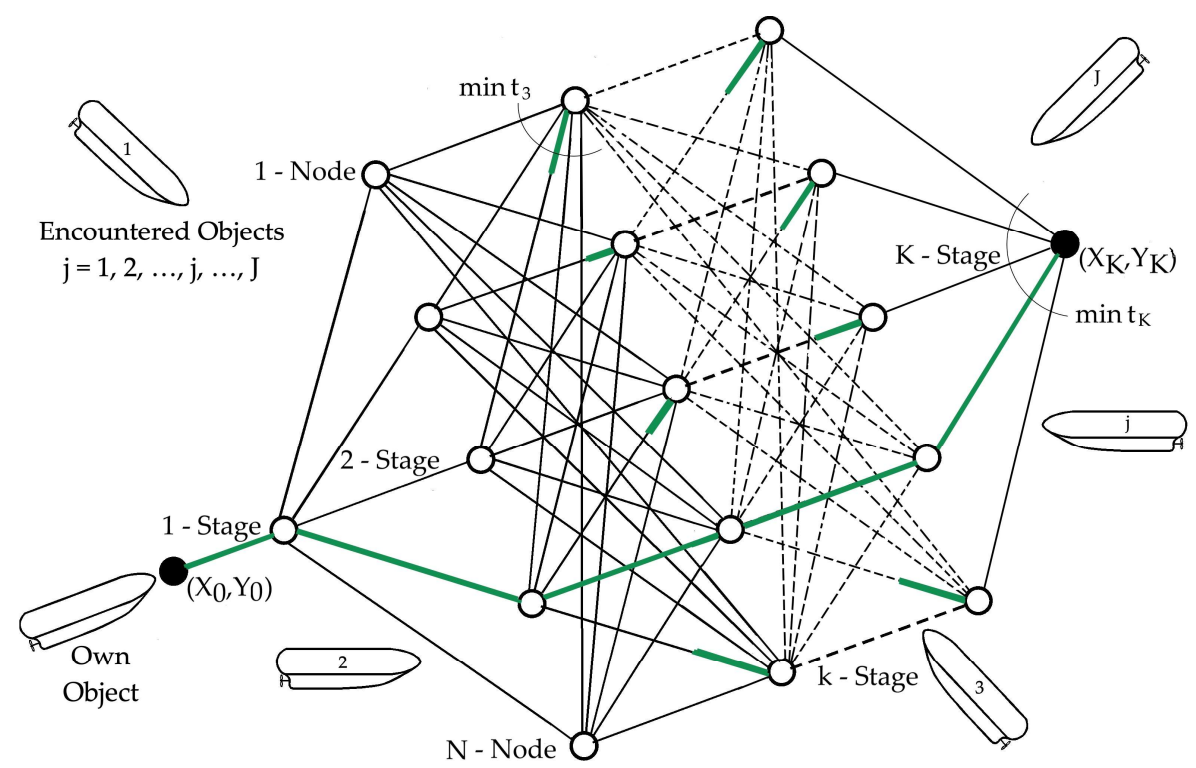

Figure 3. Dividing ship route into K stages and N nodes.

\subsection{Artificial-Neural-Network Domains of Encountered Objects}

The area of collision risk within an encountered-object domain was created in the ANN computer algorithm. In accordance with COLREGS rules for good visibility conditions at sea, the value of the safe passing distance of objects $D_{\mathrm{s}}=0.5-1.0 \mathrm{~nm}$ (nautical miles) was assumed, and the obligation to give way to objects approaching the starboard was applied. Therefore, the domain was assigned to them in the form of hexagons, parabolas, or ellipses, and, for the remaining objects, the domain was assigned in the form of circles. In conditions of restricted visibility at sea, domains with radius $D_{s}=1.0-3.0 \mathrm{~nm}$ apply to all objects. The surface area of the domain, generated by the neural network, is a function of encountered object speed and risk of collision [31,32].

In the structure of the artificial neural network, there are six components of input quantity vector $\mathrm{x}$ and one component of output quantity vector $\mathrm{y}$ :

$$
\begin{aligned}
& \mathbf{y}=F[W \mathbf{x}] . \\
& \mathbf{x}=\left[D_{\mathrm{j}} \mathrm{N}_{\mathrm{j}} \mathrm{V}_{\mathrm{j}} \psi_{\mathrm{j}} \mathrm{V} \psi\right] . \\
& \mathbf{y}=\left[\begin{array}{lllll}
0.1 & 0.3 & 0.5 & 0.7 & 0.9
\end{array}\right] \text {. }
\end{aligned}
$$

where the value 0.1 means a safe situation; 0.3 means attention; 0.5 means collision risk; 0.7 means a dangerous situation; and 0.9 means collision.

The network learning process meets the following equation:

$$
\min _{\mathrm{F}}\left\{\sum\left(\mathrm{y}_{\mathrm{k}}-\mathrm{y}_{\mathrm{ek}}\right)^{2}\right\}
$$

where $\mathrm{F}$ is the activation function form, $\mathrm{W}\left(\mathrm{W}_{1}, \mathrm{~W}_{2}, \mathrm{~W}_{3}\right)$ are the weight factors, $\mathrm{y}_{\mathrm{k}}$ is the output variable of the artificial neural network, $y_{\mathrm{ek}}$ is the reference output variable of the artificial neural network, $\Sigma$ is an average sum error of neural-network learning to the reference navigator-teacher's assessment of the navigational situation, and $\mathrm{k}$ is discrete time.

Vector components $x_{k}$ are information coming from ARPA, and vector $y_{k}$ components evaluate the collision risk value in proportion to the size of the domain area assigned to $j$ encountered object. The structure of the considered artificial neural network contains three neuron layers; nonlinear activation functions are included in the first and second layers, and a sigmoidal activation function can be found in the third output layer [33-36]. 
The MATLAB Neural Network Toolbox software was used to design the ANN network, and an error-propagation algorithm with adaptive learning pace and momentum was used to teach it. Training data were prepared by simulating navigational situations and recording the corresponding expected network answers given by about 300 experienced navigators during ARPA training courses at the Officers Training Center of the Gdynia Maritime University in Poland. To ensure data accuracy, the network learning process was based on several standard scenarios for navigational situations at sea. For each situation, each navigator chose the best option according to his own opinion; that is, subjectively, in accordance with good maritime practice, he chose an anti-collision maneuver to change the course and/or speed of the ship. In this way, the learned network represents the average experience of a larger population of navigators.

\section{Results}

Simulation studies of the DPANN algorithm were carried out for three navigational situations that differed in the number of encountered objects. Situations were recorded using information from the ARPA on a research and training ship. Registered navigational situations in which an object was involved were considered safe if the safe passing distance was 0.5 nautical miles. For the computer simulation, to get a collision situation, the safe passing distance was increased to 1.0 nautical miles. In simulation studies, the trajectory of the object was determined in good visibility at sea, so the value of the safe distance of ships in these conditions was assumed to be $D_{s}=1.0 \mathrm{~nm}$ (nautical mile). The bold part of the trajectory corresponds to a maneuver that reduced the propeller speed by $25 \%$.

\subsection{Simulation of Own-Object Steering While Passing Three Encountered Objects}

Figure 4 shows safe and optimal object trajectories, and in particular the movement of all domains in subsequent moments of time is presented to show the change in their size depending on the degree of danger of approaching objects, just like the navigator estimates in practice.
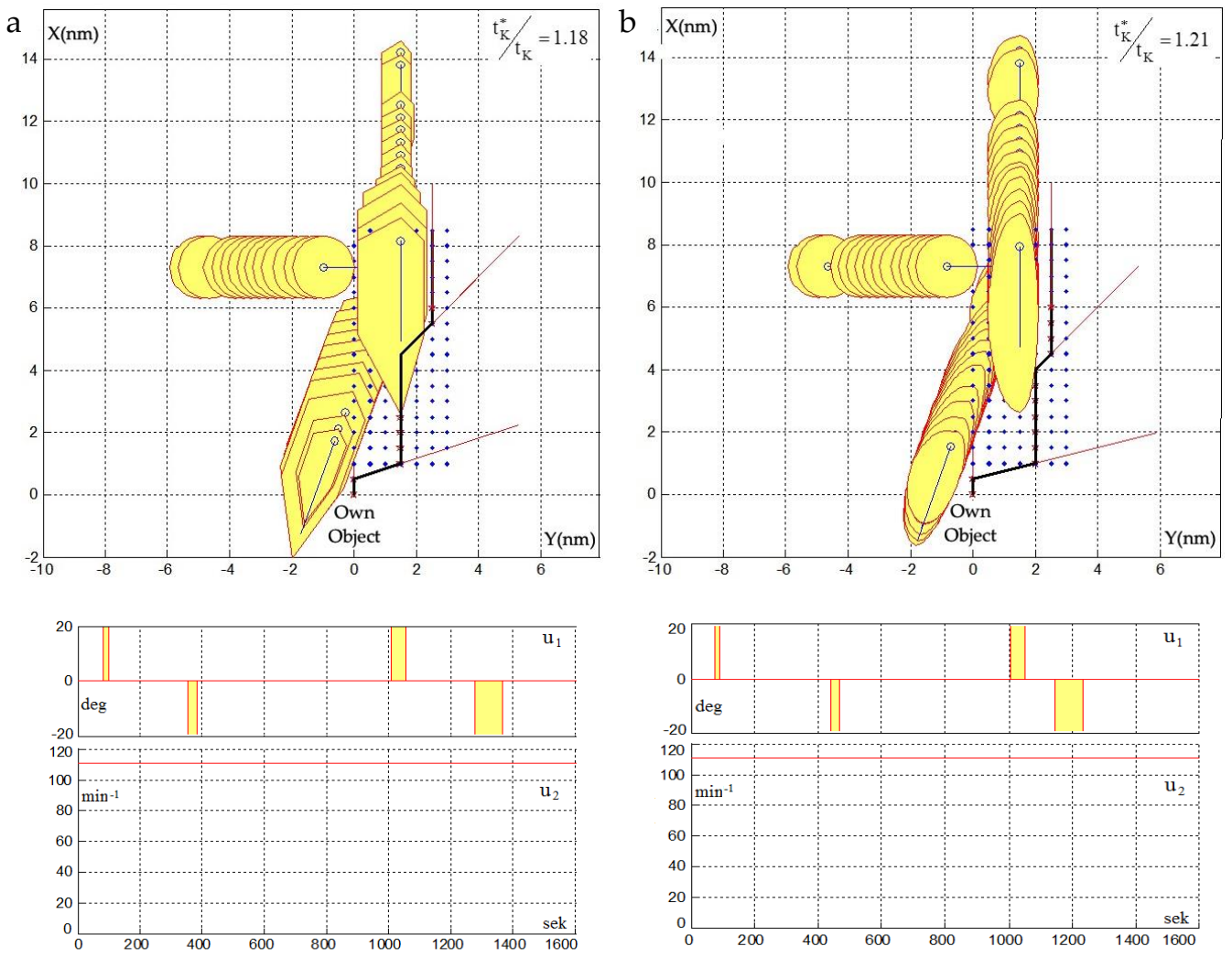

Figure 4. Cont. 

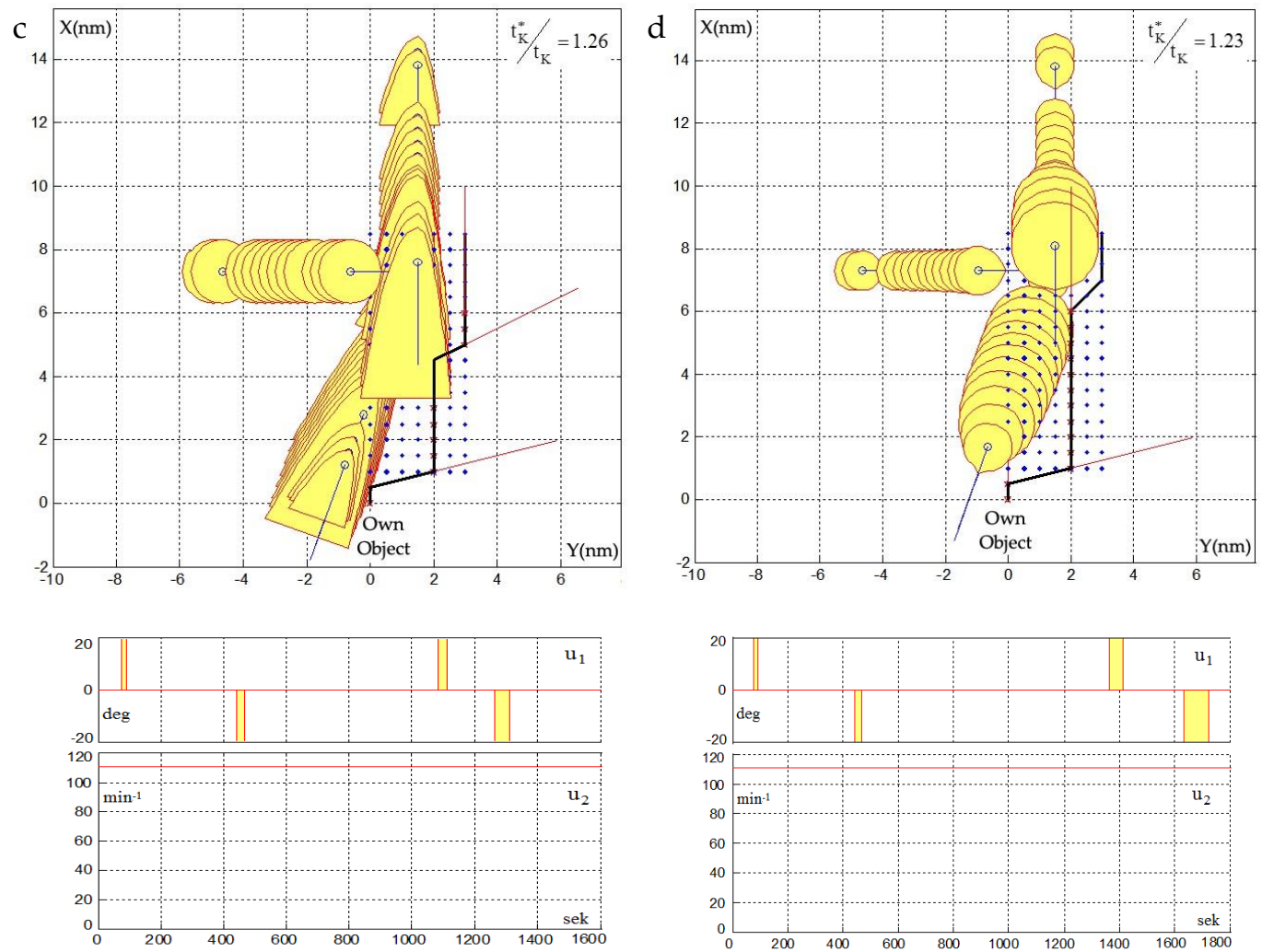

Figure 4. Computer-simulation results of safe object control in a situation with three encountered objects in good visibility at sea for domains in the form of hexagons (a), ellipses (b), parabolas (c), and circles (d). (top) Trajectory of own object; (bottom) control variables-rudder deflection $\mathrm{u}_{1}$ and screw speed $\mathrm{u}_{2}$.

\subsection{Simulation of Own-Object Steering While Passing Eighteen Encountered Objects}

Figure 5 shows the own-object trajectory and the control by means of rudder deflection and rotational speed of the propeller.
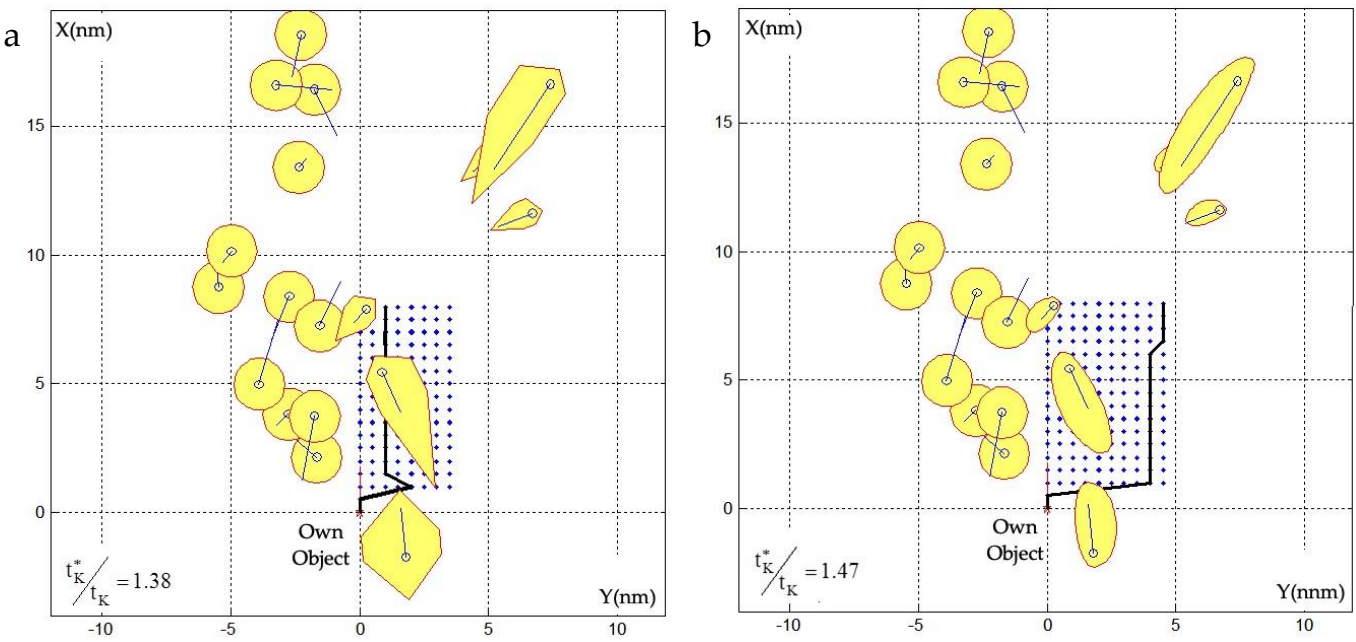

Figure 5. Cont. 

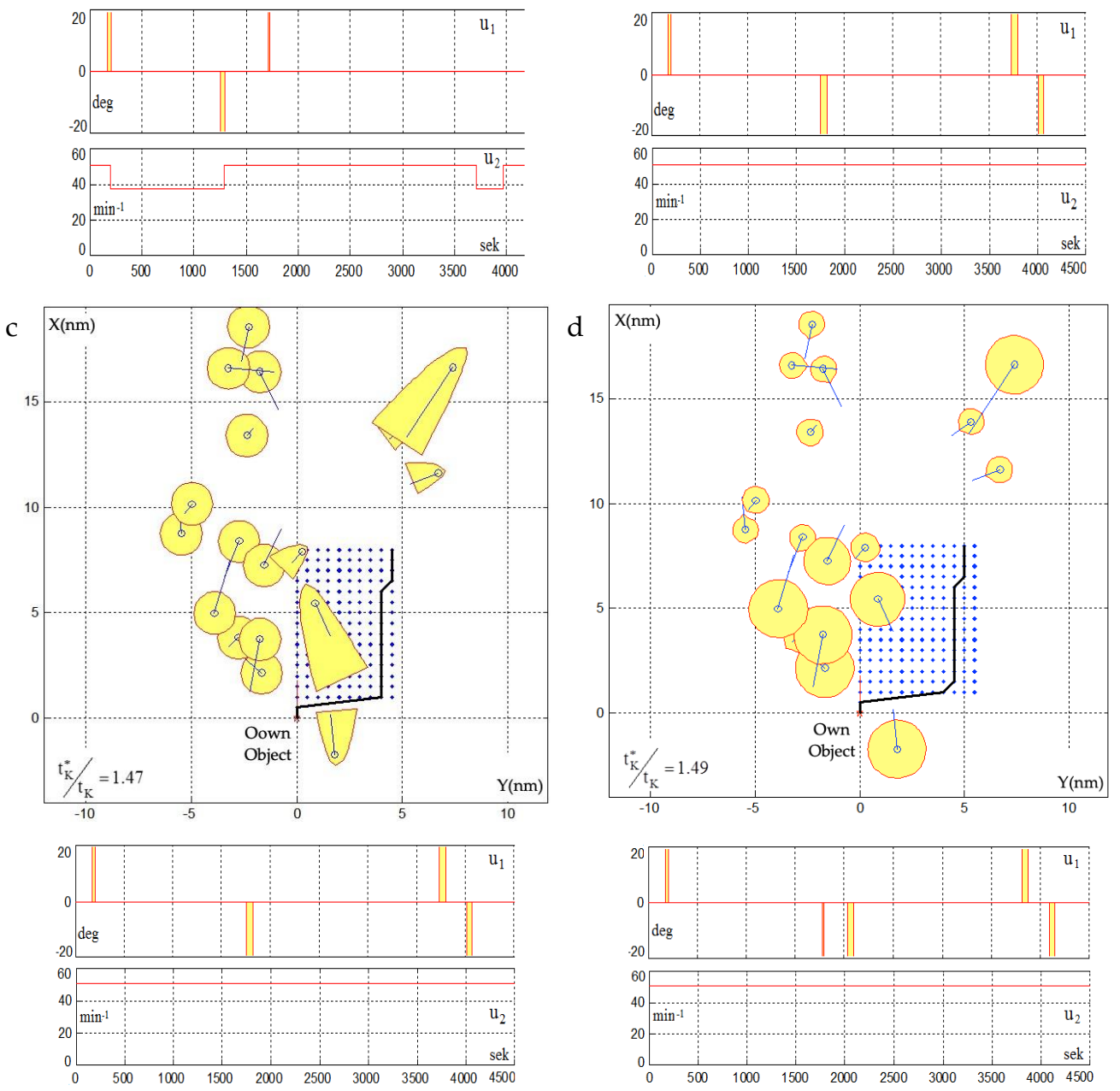

Figure 5. Computer-simulation results of own-object trajectories in a situation with 18 met objects in good visibility at sea for domains in the form of hexagons (a), ellipses (b), parabolas (c), and circles (d). (top) Trajectory of own object; (bottom) control variables-rudder deflection $u_{1}$ and screw speed $u_{2}$.

\subsection{Simulation of Own-Object Steering While Passing Sixty Encountered Objects}

Figure 6 shows the own-object trajectory and the control by means of rudder deflection and rotational speed of the propeller.

a

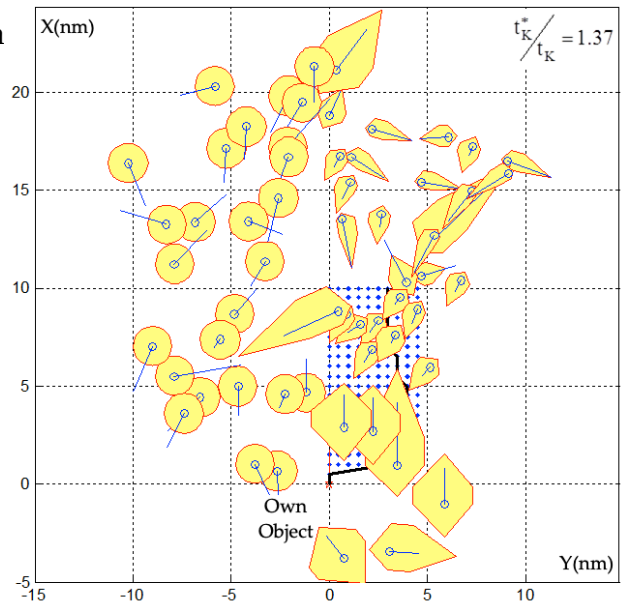

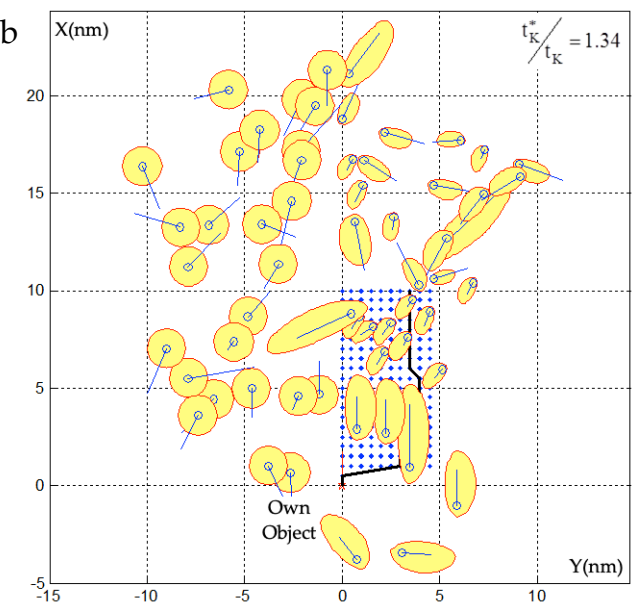

Figure 6. Cont. 

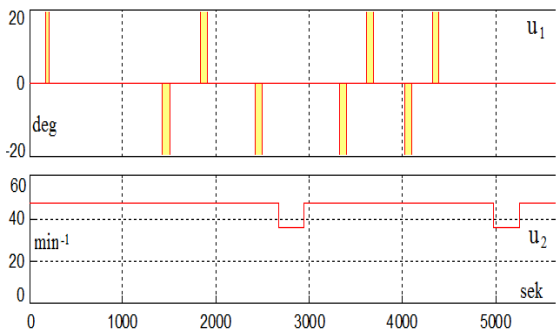

C
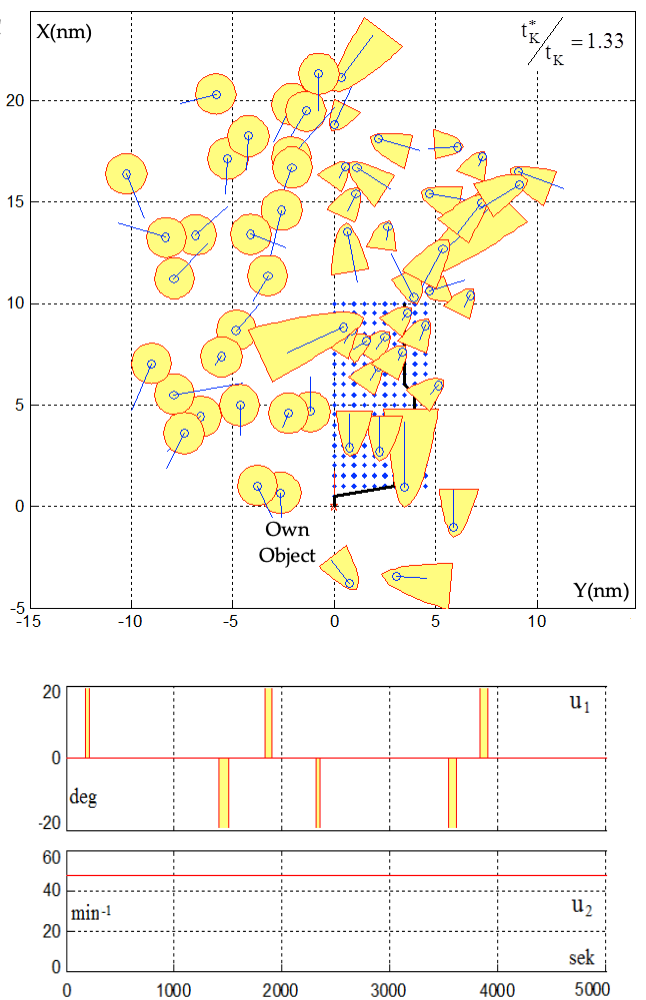
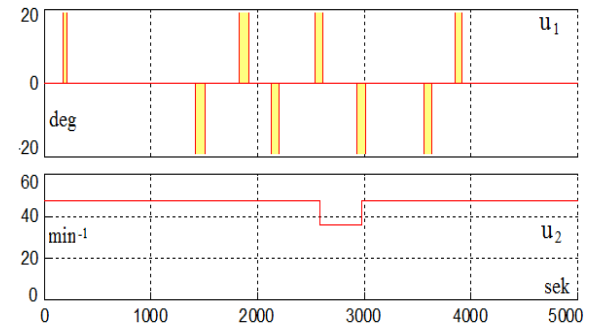

d
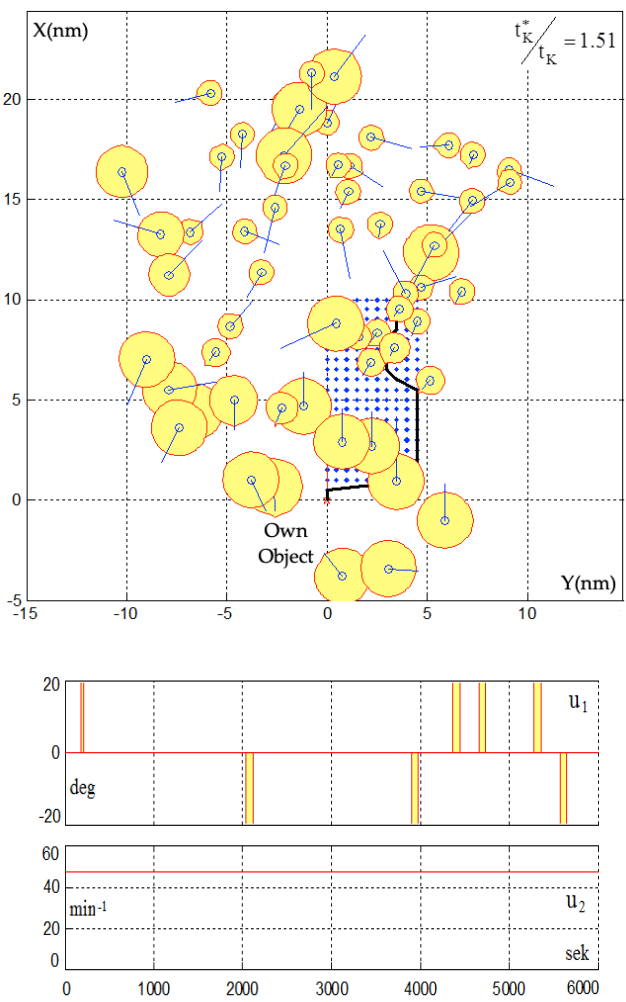

Figure 6. Computer-simulation results of own-object trajectories in a situation with 60 passing objects in good visibility at sea for domains in the form of hexagons (a), ellipses (b), parabolas (c), and circles (d). (top) Trajectory of own object; (bottom) control variables-rudder deflection $\mathrm{u}_{1}$ and screw speed $\mathrm{u}_{2}$.

\section{Discussion}

Traditionally, by using the ARPA, the navigator can select a single anti-collision maneuver, taking into account the movement of a dangerous ship, but must then check it for other objects and possibly change the selected maneuver. However, the use of the DPANN algorithm allows the calculation of the trajectory of one's own facility that provides the smallest deviation from the set cruise route as a sequence of subsequent necessary maneuvers with respect to all tracked objects.

Considering the different dynamics of the object when changing its course and speed, time-optimal control of its movement is first achieved by means of rudder deflection. It is only when there is no possible safe course change that the speed of the object is reduced, which is realized by reducing the rotational speed of the propeller by $25 \%$. Therefore, with the increase in the number of encountered objects, it is more difficult to find an optimal and safe trajectory of the object when only steering the rudder. The calculation time of the algorithm is between a few and a dozen or so seconds, depending on the number of encountered objects. However, the more objects encountered, the more unacceptable nodes in the dynamic programming grid that are rejected by the ANN procedure and the shorter the calculation time. This is one of the advantages of using Bellman's practical principle of optimality-the 
more limitations, the more the search area of acceptable solutions decreases and the faster the optimal solution to the problem is found.

Figure 7 shows the relative value of time needed for safe and optimal passing with met objects as a function of the reference value for safe passing distance in relation to various forms of domains assigned to encountered objects.

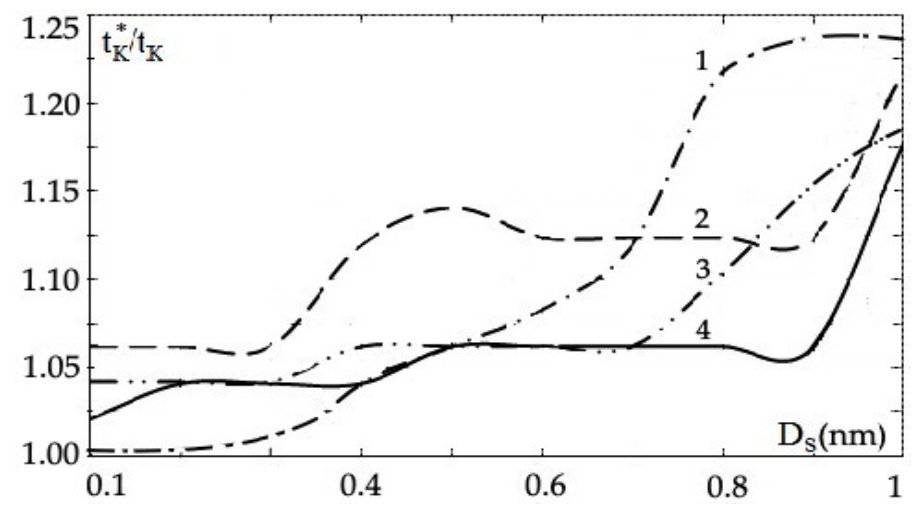

Figure 7. Dependence of optimal time of own-object movement needed for safe passing of other objects as a value function of the previously adopted safe passing distance for shaped domains: 1, circle; 2 , parabola; 3, hexagon; 4, ellipse.

The shortest time needed to safely pass objects is provided by an ellipse-shaped domain.

Figure 8 illustrates the variability of the relative time value of the safe movement of the object for different distance values between nodes in the dynamic-programming grid.

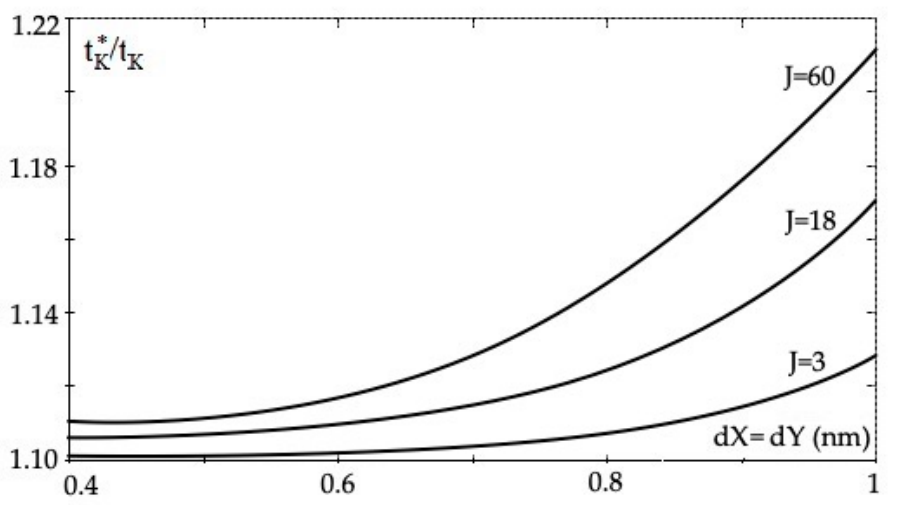

Figure 8. Dependence of the optimal-time value needed for safe passing of objects on the node-distribution density in situations J encountered objects.

In practice, the degree of node-distribution density in the dynamic-programming grid of the object trajectory is a compromise between a long calculation time and determined-trajectory accuracy.

\section{Conclusions}

The task of optimizing the safe management of own-object movement in situations of passing many met objects was presented, which allowed us to formulate the following conclusions. The use of radar remote sensing to identify object movement parameters allows the synthesis of an appropriate algorithm to support the navigator in determining the safe trajectory of the object as a sequence of subsequent changes in its course and speed. Presentation of encountered-objects' movement in the form of moving neural domains of variable size, depending on the distance and time of approaching objects, reflects the navigator's subjectivity in the assessment of collision risk. The use of several hundred navigator officers to teach an artificial neural network causes it to interpret-in the computational 
algorithm of the domain of danger of met objects-as if it is done by a single experienced navigator. Analysis of possible domain shapes indicates the possibility of their adaptation to open or restricted waters. Node density in the dynamic-programming trajectory of the object is a compromise between calculation time and object-route accuracy.

The essence of the article is the use of an artificial neural network to map the navigator's subjectivity in the assessment of a collision situation, and the optimization method in the form of dynamic programming is only a tool in the synthesis of the entire calculation algorithm.

This work did not exhaust all issues related to the safe management of the movement of objects at sea. In subsequent studies, consideration of the safe object control sensitivity analysis to the inaccuracy of information from navigation devices, changes in object-dynamics parameters, and the impact of hydrometeorological disturbances should be undertaken.

Funding: This research was funded by a research project of Gdynia Maritime University in Poland, No. WE/2020/PZ/02: "Methods of static and dynamic optimization of ship movement control".

Conflicts of Interest: The author declares no conflict of interest.

\section{References}

1. Graziano, M.D.; D’Errico, M.; Rufino, G. Wake Component Detection in X-Band SAR Images for Ship Heading and Velocity Estimation. Remote Sens. 2016, 8, 498. [CrossRef]

2. Huang, X.; Yang, W.; Zhang, H.; Xia, G.S. Automatic Ship Detection in SAR Images Using Multi-Scale Heterogeneities and an a Contrario Decision. Remote Sens. 2015, 7, 7695-7711. [CrossRef]

3. Bist, D.S. Safety and Security at Sea; Butterworth Heinemann: Oxford, UK, 2000; ISBN 0-75064-774-4.

4. Szlapczynski, R.; Szlapczynska, J. A method of determining and visualizing safe motion parameters of a ships navigating in restricted waters. Ocean Eng. 2017, 129, 363-373. [CrossRef]

5. Lyu, H.; Yin, Y. Fast Path Planning for Autonomous Ships in Restricted Waters. Appl. Sci. 2018, 8, 2592. [CrossRef]

6. Deng, W.; Gan, L.; Zhou, C.; Zheng, Y.; Liu, M.; Zhang, L. Study on Path Planning of Ship Collision Avoidance in Restricted Water base on AFS Algorithm. In Proceedings of the 27th Int. Ocean and Polar Engineering Conf., San Francisco, CA, USA, 25-30 June 2017; pp. 1-7, ID: ISOPE-I-17-280.

7. Lebkowski, A. Evolutionary methods in the management of vessel traffic. In Proceedings of the Int. Conf. on Marine Navigation and Safety of Sea Transportation, Gdynia, Poland, 17-19 June 2015; pp. 259-266.

8. Lazarowska, A. Safe Ship Trajectory Planning Based on the Ant Algorithm-The Development of the Method. In Activities in Navigation: Marine Navigation and Safety of Sea Transportation; CRC Press: Boca Raton, FL, USA, 2015; pp. 153-160. [CrossRef]

9. Tomera, M. Ant Colony Optimization Algorithm Applied to Ship Steering Control. Procedia Comput. Sci. 2014, 35, 83-92. [CrossRef]

10. Dinh, G.H.; Im, N.K. Study on the Construction of Stage Discrimination Model and Consecutive Waypoints Generation Method for Ship's Automatic Avoiding Action. Int. J. Fuzzy Log. Intell. Syst. 2017, 17, 294-306. [CrossRef]

11. Lyu, H.; Yin, Y. COLREGS-Constrained Real-time Path Planning for Autonomous Ships Using Modified Artificial Potential Fields. J. Navig. 2019, 72, 588-608. [CrossRef]

12. Rocha, A.F. Neural Nets - Theory of Brain a Machines; Springer: Berlin, Germany; New York, NY, USA; ISBN 0-8493-2643-5.

13. Hwang, J.I.; Chae, S.H.; Kim, D.; Jung, H.S. Application of Artificial Neural Networks to Ship Detection from X-Band Kompsat-5 Imagery. Appl. Sci. 2017, 7, 961. [CrossRef]

14. Kang, M.; Ji, K.; Leng, X.; Lin, Z. Contextual Region-Based Convolutional Neural Network with Multilayer Fusion for SAR Ship Detection. Remote Sens. 2017, 9, 860. [CrossRef]

15. Collingwood, A.; Treitz, P.; Charbonneau, F.; Atkinson, D.M. Artificial Neural Network Modeling of High Arctic Phytomass Using Synthetic Aperture Radar and Multispectral Data. Remote Sens. 2014, 6, 2134-2153. [CrossRef]

16. Lenart, A.S. Analysis of Collision Threat Parameters and Criteria. J. Navig. 2015, 68, 887-896. [CrossRef] 
17. Borkowski, P. The Ship Movement Trajectory Prediction Algorithm Using Navigational Data Fusion. Sensors 2017, 17, 1432. [CrossRef] [PubMed]

18. Liu, Z.; Wu, Z.; Zheng, Z. A Cooperative Game Approach for Assessing the Collision Risk in Multi-Vessel Encountering. Ocean Eng. 2019, 187, 106175. [CrossRef]

19. Lisowski, J. Optimization-supported decision-making in the marine game environment. Solid State Phenomena 2014, 210, 215-222. [CrossRef]

20. Colley, B.A.; Curtis, R.G.; Stockel, C.T. Manoeuvring Times, Domains and Arenas. J. Navig. 1983, 36, 324-328. [CrossRef]

21. Cross, S.J. Objective Assessment of Maritime Simulator Training. In Proceedings of the International Conference the Development and Implementation of International Maritime Training Standards, Malmo, Sweden, 11-13 June 1994.

22. Davis, P.V.; Dove, M.J.; Stockel, C.T. A computer simulation of marine traffic using domains and areas. J. Navig. 1980, 33, 215-222. [CrossRef]

23. Goodvin, E.M.A. Statistical study of ship domains. J. Navig. 1975, 28, 328-334. [CrossRef]

24. Guenin, B.; Konemann, J.; Tuncel, L.A. Gentle Introduction to Optimization; Cambridge University Press: Cambridge, UK, 2014; ISBN 978-1-107-05344-1.

25. Speyer, J.L.; Jacobson, D.H. Primer on Optimal Control Theory; SIAM: Toronto, ON, Canada, 2010; ISBN 978-0-898716-94-8.

26. Yong, J. Optimization Theory-A Concise Introduction; World Sc.: New York, NY, USA, 2018; ISBN 978-981-3237-64-3.

27. Bellman, R.E. Dynamic Programming; Dover Publication: Mineola, NY, USA, 2003; ISBN 0-486-42809-5.

28. Lew, A.; Mauch, H. Dynamic Programming-A Computational Tool; Springer: Berlin, Germany, 2007; ISBN 978-3-540-37014-7.

29. Geng, X.; Wang, Y.; Wang, P.; Zhang, B. Motion of maritime autonomous surface ships by dynamic programming for collision avoidance and speed optimization. Sensors 2019, 19, 434. [CrossRef] [PubMed]

30. Witkowska, A.; Smierzchalski, R. Adaptive Dynamic Control Allocation for Dynamic Positioning of Marine Vessel Based on Backstepping Method and Sequential Quadratic Program. Ocean Eng. 2018, 163, 570-582. [CrossRef]

31. Stateczny, A. Neural Manoeuvre Detection of the Tracked Target in ARPA Systems. In Proceedings of the IFAC Conference on Control Applications in Marine Systems, Glasgow, Scotland, 19-21 June 2011; pp. 209-214.

32. Wlodarczyk-Sielicka, M.; Lubczonek, J.; Stateczny, A. Comparison of selected clustering algorithms of raw data obtained by interferometric methods using artificial neural networks. In Proceedings of the 17th Int. Radar Symp., Krakow, Poland, 10-12 May 2016.

33. Hertz, J.; Krogh, A.; Palmer, R.G. Introduction to the Theory of Neural Computation; CRC Press: Boca Raton, FL, USA, 2018; ISBN 978-0-201-51560-1.

34. Hunt, K.J.; Irwin, G.R.; Warwick, K. Neural Network Engineering in Dynamic Control Systems; Advances in Industrial Control Series; Springer: Berlin, Germany, 1995; ISBN 3-540-19973-X.

35. Leondes, C.T. Control and Dynamic Systems, Neural Network Systems Techniques and Applications; Academic Press: New York, NY, USA, 1998; Volume 7, ISBN 978-0124438675.

36. Francelin, R.; Kacprzyk, J.; Gomide, F. Neural Network Based Algorithm for Dynamic System Optimization. Asian J. Control 2001, 3, 131-142. [CrossRef]

(C) 2020 by the author. Licensee MDPI, Basel, Switzerland. This article is an open access article distributed under the terms and conditions of the Creative Commons Attribution (CC BY) license (http://creativecommons.org/licenses/by/4.0/). 